\title{
Gottfried Huber-Pestalozzi
}

\section{zum fünfundsiebzigsten Geburtstag}

Wenn Herr Dr. phil., Dr. med. et Dr. rer. nat. h. c. GoTTFRIED HubERPestalozzI am 3I. März I952, d. h. beim Übertritt in sein sechsundsiebzigstes Lebensjahr, Rückschau hielt auf die Leistung, die seinem Geiste und seiner Hände Werk entsprungen ist, dann durfte er wohl mit Befriedigung und Stolz feststellen, dass die Ernte reich ausfiel. Wir anderen aber, die den Arzt und Naturforscher am Werk sehen, stehen erstaunt ob der Feststellung, wieviel - abseits vom akademischen Betrieb der Hochschule ein Mann zu vollbringen vermag, wenn er, von gutem Forschergeist getrieben, seine Zeit voll zu nützen weiss.

Am damaligen Eidg. Polytechnikum bildete sich GotTFried HubER zum Fachlehrer in Naturwissenschaften aus, aber da die Aussichten, bald ein befriedigendes Tätigkeitsfeld zu finden, gering waren, entschloss er sich zum Medizinstudium, nach dessen Abschluss er als angehender Spezialarzt mehr als 30 Jahre lang mit Erfolg und Befriedigung in Zürich eine weitreichende Praxis führte. Dabei kam ihm seine naturwissenschaftliche Begabung in hohem Masse zustatten. Darüber hinaus aber blieb das Bedürfnis nach forscherischer Betätigung in ihm lebendig. Prof. CARL SCHRÖTER hatte das Interesse für die Kleinlebewelt der Gewässer in ihm geweckt, und schon die Promotionsarbeit über die Biologie der Montigglerseen im Südtirol liess erkennen, dass GotTFRIEd HUBER berufen sein werde, in der Diskussion um die aktuellen Fragen der Gewässerbiologie massgeblich mitzureden. Durch seine Arbeit zeigte er, wie man auch ohne grosse Apparaturen und Einrichtungen nützliche Wissenschaft betreiben kann, wenn man nur die Probleme richtig zu wählen weiss, und da die Arbeit am Mikroskop für ihn Ausspannung und Erholung bedeutete, so entstand als Frucht ungezählter durchwachter Nächte, bis zum letzten ausgenützter Ferienwochen und wohlorganisierter Auslandreisen ein schöner Strauss von Arbeiten, die insbesondere die Zusammensetzung des Planktons zahlreicher Seen zum Gegenstand haben. So schuf er zum Teil monographische Bearbeitungen verschiedener Alpenseen (Bernina, Samnaun) und stehender Gewässer des Alpenvorlandes (Zürichsee, Walensee, Muzzanersee); aber auch zahlreiche Sammelmaterialien verschiedener 
Tropenreisenden aus Ostindien, Afrika usw. fanden durch ihn eine sorgfältige Bearbeitung. Aus den entwicklungsgeschichtlichen Studien an einzelnen Planktonorganismen sind die in Zusammenarbeit mit dem Zürcher Apotheker Dr. F. NIPKow durchgeführten Untersuchungen über den Lebenszyklus von Ceratium birundinella besonderer Erwähnung wert.

Unter den schweizerischen Fachleuten der Hydrobiologie blieb HuBERPestalozzr lange Zeit ein Einzelgänger. Darum nahmen seine Arbeiten meist den Weg in ausländische Fachzeitschriften. Dort aber fanden sie die verdiente Beachtung, und in den Limnologenkreisen des Auslandes gewann sein Name einen ausgezeichneten Klang. Es ist darum keineswegs verwunderlich, dass der Herausgeber des grossangelegten Werkes Die Binnengemässer, Prof. A. ThienemanN, einen bedeutsamen Teil davon, nämlich die Bearbeitung des "Phytoplanktons der Erde», in die Hände HubER-Pestalozzis legen konnte. Dies bedeutet eine Aufgabe von sehr beträchtlichem Ausmass. Dass ihr der Autor aber durchaus gewachsen ist, beweisen die bereits vorliegenden ersten 4 Bände, die bei den Fachleuten durchweg eine sehr gute Aufnahme gefunden haben. Bereits liegen weitere Lieferungen im Manuskript vor. Wenn auch sie einmal gedruckt sind, das vollständige Werk also vorliegt, dann werden wir alle, die wir diese Bücher in unserer täglichen Arbeit als Rüstzeug benützen, Grund haben; dankbar und stolz darauf zu sein, dass durch einen unserer Landsleute diese keineswegs leichte Aufgabe gemeistert wurde.

Zusammen mit seiner Gattin, in der GotTFrued Huber eine liebe, treue und begabte Mitarbeiterin besass, sah man ihn bis vor dem Kriege regelmässig bei den grossen limnologischen Auslandstagungen vertreten. Dort hatte sein Wort stets einen guten Klang. Dies kam besonders deutlich zum Ausdruck, als die Internationale Vereinigung für theoretische und angewandte Limnologie ihrem schweizerischen Landesvertreter die Naumann-Medaille verlieh.

Erst verhältnismässig spät, aber aus dem notwendigen Bestreben heraus, die in der Schweiz auf dem Gebiete der Limnologie getrennt arbeitenden Kräfte zu gemeinschaftlichem Werk zusammenzufassen, wurde die Mitarbeit dieses erfolgreichen Privatgelehrten gesucht. So wirkt er seit einer Reihe von Jahren tüchtig mit an den grossen Aufgaben der Hydrobiologischen Kommission der Schweizerischen Naturforschenden Gesellschaft. In richtiger Würdigung seiner Verdienste um die limnologische Wissenschaft brachte das Heimatland dem unermüdlichen Forscher seinen Dank zum Ausdruck in der Verleihung des Titels eines Ehrendoktors der Naturwissenschaften durch die Eidgenössische Technische Hochschule. 
Wenn sich in neuerer Zeit zwischen zahlreichen ausländischen Limnologen und ihren schweizerischen Kollegen herzliche Verbindungen entwickelten, die unserer Wissenschaft auf internationalem Boden zum Nutzen gereichen, so zeigt sich in dieser Tatsache vielleicht die wertvollste Frucht jener schönen Tagung der Internationalen Vereinigung für Limnologie, die unter der Leitung von GotTFRIEd HubER-PESTALOzzI im Sommer 1948 in der Schweiz durchgeführt wurde.

Möge dem fünfundsiebzigjährigen, geistig und körperlich noch gleichermassen rüstigen und regsamen Gelehrten noch eine recht lange Reihe von guten Jahren der Gesundheit, des Wohlergehens und der fruchtbaren Arbeit beschieden sein. 